\title{
Liraglutide restores late cardioprotective effects of remote preconditioning in diabetic rats via activation of hydrogen sulfide and nuclear factor erythroid 2-related factor 2 signaling pathway
}

\author{
Lingling Wang ${ }^{1}$, Yinyan Tang ${ }^{2}$, Huimin $\mathrm{He}^{3}$ iD, Weirong Wei, ${ }^{4}$, \\ 1.MM. Jiangxi Provincial People's Hospital - Department of Cardiology - Nanchang, (Jiangxi), China. \\ 2.MM. The Forth People's Hospital of Yongzhou - Department of Cardiovascular Medicine - Yangzhou (Hunan), China. \\ 3.MM. The Forth People's Hospital of Yongzhou - Department of Cardiovascular Medicine - Yangzhou (Hunan), China. \\ 4.MM. Jiangxi Provincial People's Hospital - Department of Cardiology - Nanchang, (Jiangxi), China.
}

\begin{abstract}
Purpose: The present study explored the influence of liraglutide on remote preconditioning-mediated cardioprotection in diabetes mellitus along with the role of nuclear factor erythroid 2-related factor 2 (Nrf2), hypoxia inducible factor ( $\mathrm{HIF}-1 \alpha)$ and hydrogen sulfide $\left(\mathrm{H}_{2} \mathrm{~S}\right)$. Methods: Streptozotocin was given to rats to induce diabetes mellitus and rats were kept for eight weeks. Four cycles of ischemia and reperfusion were given to hind limb to induce remote preconditioning. After $24 \mathrm{~h}$, hearts were isolated and subjected to $30 \mathrm{~min}$ of ischemia and $120 \mathrm{~min}$ of reperfusion on Langendorff system. Liraglutide was administered along with remote preconditioning. Cardiac injury was assessed by measuring the release of creatine kinase (CK-MB), cardiac troponin (cTnT) and development of left ventricular developed pressure. After ischemia-reperfusion, hearts were homogenized to measure the nuclear cytoplasmic ratio of Nrf2, $\mathrm{H}_{2} \mathrm{~S}$ and HIF-1 $\alpha$ levels. Results: In diabetic rats, there was more pronounced injury and the cardioprotective effects of remote preconditioning were not observed. Administration of liraglutide restored the cardioprotective effects of remote preconditioning in a dose-dependent manner. Moreover, liraglutide increased the $\mathrm{Nrf2}, \mathrm{H}_{2} \mathrm{~S}$ and $\mathrm{HIF}$-1 $\alpha$ levels in remote preconditioning-subjected diabetic rats. Conclusion: Liraglutide restores the lost cardioprotective effects of remote preconditioning in diabetes by increasing the expression of $\mathrm{Nrf2}, \mathrm{H}_{2} \mathrm{~S}$ and HIF-1 $\alpha$.
\end{abstract}

Key words: Liraglutide. Diabetes mellitus. Reperfusion injury. Hypoxia inducible factor. Langendorff.

\footnotetext{
*Corresponding author: bblc62130@sina.com | +86-15112009654
}

Received: Oct 19, 2020 | Review: Dec 21, 2020 | Accepted: Jan 23, 2021

Conflict of interest: Nothing to declare.

Research performed at Department of Cardiology, Jiangxi Provincial People's Hospital, China. 


\section{Introduction}

Diabetes mellitus is a chronic metabolic disorder, which is characterized by disturbance in glucose metabolism. Apart from short term effects of diabetes, long-standing uncontrolled hyperglycemia in diabetes produces a number of complications, including increase in the tendency to develop ischemia-reperfusion induced myocardial injury ${ }^{1,2}$. Remote preconditioning a therapeutic strategy in which short episodes of ischemia and reperfusion to an organ other than heart (nontarget or remote organ) confers protection to heart from sustained ischemia-reperfusion injury ${ }^{3}$. This therapeutic strategy has been used in preclinical as well in clinical setup to confer protection to heart against ischemiareperfusion injury ${ }^{4,5}$. Amongst the different problems of longstanding diabetes, the usefulness of remote preconditioning to trigger cardioprotection is abolished significantly in diabetic condition ${ }^{6}$.

Liraglutide is glucagon-like peptide 1 agonist (GLP-1 agonist) and it has been used to manage diabetes mellitus type $2^{7}$. It is also been increasingly used to manage weight in obese people ${ }^{8}$ with potential weight loss benefits, approved for the treatment of type 2 diabetes (T2D. Apart from it, liraglutide has been shown to exert neuroprotective effect and preserve cognitive functions ${ }^{9}$, decrease renal fibrosis ${ }^{10}$ and improve heart contractility ${ }^{11}$ and decrease heart remodeling ${ }^{12}$. There are important mediators revealed by different scientists that are important in inducing cardioprotective effects of remote preconditioning. Amongst these, the role of Nrf2 ratio ${ }^{13,14}, \mathrm{HIF}-1 \alpha^{15,16}$ and $\mathrm{H}_{2} \mathrm{~S}^{17}$ has been very well documented in remote preconditioning-induced cardioprotection. Studies have shown that liraglutide promotes angiogenesis through increase in HIF-1 $\alpha$ and vascular endothelial growth factor (VEGF) levels ${ }^{18}$. Moreover, it is also shown that liraglutide increases the expression of Nrf2, a transcriptional factor involved in increasing antioxidant enzymes, in producing beneficial effects ${ }^{19,20}$.

Based on these, the present study was designed to explore the influence of liraglutide on remote preconditioningmediated cardioprotection in long standing diabetes mellitus. Moreover, the study also explored the possible involvement of $\mathrm{Nrf2}$, $\mathrm{HIF}-1$ and $\mathrm{H}_{2} \mathrm{~S}$ in liraglutide-mediated effects in remote preconditioning-subjected diabetic rats.

\section{Methods}

\section{Animals and drugs}

The experimental protocol was approved by Institutional Ethical Committee of Jiangxi Provincial People's Hospital, with ethic number: 202005088779C09. Wistar albino rats (200-250g) were used for this study and the animals were kept in the standardized laboratory facilities. The kits for estimating the levels of creatine kinase (CK-MB), cardiac troponin T (cTnT), HIF-1 $\alpha$ and Nrf-2 were procured from MyBioSource, Inc., San Diego, CA, USA.

\section{Induction of diabetes mellitus}

A single dose of streptozotocin (STZ) $(60 \mathrm{mg} / \mathrm{kg}$ i.v.) was administered to rats to induce diabetes mellitus ${ }^{21}$. The animals were kept for eight weeks to allow the onset of diabetic complications including increase in the tendency to develop ischemia-reperfusion injury. The blood glucose levels were quantified before STZ injection and at the end of the $8^{\text {th }}$ week.

\section{Perfusion of isolated hearts on the Langendorff system and assessment of myocardial injury}

The animals were sacrificed by cervical dislocation and hearts were isolated to perfuse on the Langendorff apparatus, using Krebs-Henseleit solution. The inflow of Krebs solution was stopped for $30 \mathrm{~min}$ to induce global ischemia. Thereafter, the flow was reinstated for reperfusion for $21 \mathrm{~min}^{22}$. The extent of ischemia-reperfusion injury was assessed by measuring the release of heart-specific $\mathrm{CK}-\mathrm{MB}$ and $\mathrm{CTnT}$ from the heart to the coronary effluent using commercially available diagnostic kits. Moreover, the functional assessment of heart was evaluated by measuring left ventricular developed pressure (LVDP) in the heart using a pressure transducer.

\section{Remote ischemic preconditioning (RIP)}

Under anesthesia (thiopental sodium $45 \mathrm{mg} / \mathrm{kg}$ i.p.), the left hind limb of rats was tied with neonatal blood pressure cuff. The cuff was filled with air up to pressure $160 \mathrm{~mm}$ of $\mathrm{Hg}$ to stop the flow of blood (hind limb ischemia) for $5 \mathrm{~min}$. Thereafter, the cuff was deflated completely to restore the blood flow to hind limb (hind limb reperfusion) for $5 \mathrm{~min}$. Such four alternate cycles of ischemia and reperfusion to the hind limb constituted remote preconditioning. After $24 \mathrm{~h}$, the rats were sacrificed to isolate hearts, which were perfused on the Langendorff apparatus ${ }^{3}$.

\section{Assessment of nuclear cytoplasmic ratio of Nrf2, myocardial $\mathrm{H}_{2} \mathrm{~S}$ and HIF-1 $\alpha$ levels}

After ischemia-reperfusion injury, the hearts were isolated for biochemical estimations. One half of the heart portion was homogenized in phosphate buffer saline (PBS, $\mathrm{pH}:$ 7.4). It was followed by centrifugation at $5000 \mathrm{~g}$ for $15 \mathrm{~min}$ to obtain clear supernatant solution. The levels of $\mathrm{H}_{2} \mathrm{~S}$ and HIF- $1 \alpha$ were determined in clear supernatant 
solution. The levels of $\mathrm{H}_{2} \mathrm{~S}$ were measured in the heart homogenates following ischemia-reperfusion injury using reverse phase high-performance liquid chromatography (HPLC) method and data were represented as $\mu \mathrm{M} / \mathrm{mg}$ of protein. The levels of proteins in the heart homogenate were measured using Folin-Lowry method. The levels of HIF-1 $\alpha$ were also determined in supernatant solution using ELISA kit. The other half portion of the heart was used to quantify nuclear cytoplasmic ratio of Nrf2. The nuclear and cytoplasmic fractions were separated using an extraction kit (BioVision, USA). The levels of Nrf2 were assessed in the supernatant using commercially available ELISA kits.

\section{Design}

Nine experimental groups were used and each group comprised of eight rats. The groups included: normal control (group I), in which no intervention was done and heart was isolated for biochemical estimations; nondiabetic control (group II), in which hearts were isolated from nondiabetic rats and subjected to ischemia-reperfusion injury; diabetic control (group III), in which hearts of diabetic rats were subjected to ischemia-reperfusion injury; RIP in nondiabetic (group IV), in which RIP stimulus was given to nondiabetic rats; RIP in diabetic (group V), in which RIP stimulus was given to diabetic rats; liraglutide $(0.2 \mathrm{mg} / \mathrm{kg})$ and RIP in diabetic (group VI), in which liraglutide $(0.2 \mathrm{mg} / \mathrm{kg}$ ) was injected along with RIP stimulus in diabetic rats; liraglutide $(0.4 \mathrm{mg} / \mathrm{kg}$ ) and RIP in diabetic (group VII) in liraglutide $(0.4 \mathrm{mg} / \mathrm{kg})$ was injected along with RIP stimulus in diabetic rats; liraglutide $(0.4 \mathrm{mg} / \mathrm{kg})$ in nondiabetic control (group VIII), in which liraglutide was injected in nondiabetic animals, not subjected to RIP stimulus; liraglutide $(0.4 \mathrm{mg} / \mathrm{kg})$ and RIP in nondiabetic (group IX), in which liraglutide was injected along with RIP stimulus in nondiabetic rats.

\section{Statistical analysis}

Mean \pm S.D. was used to represent the data. The data of CK-MB, cTnT, LVDP, blood glucose levels were statistically compared using two-way repeated measure ANOVA. The data of other parameters were compared using one-way ANOVA. Tukey's post hoc test was employed for multiple comparisons. $\mathrm{P}<0.05$ was considered to be statistically significant.

\section{Results}

\section{Effect of diabetes on ischemia-reperfusion induced heart injury}

There was a significant rise in the fasting blood glucose levels in streptozotocin-injected rats as compared to nondiabetic rats, $p<0.001$ (Fig. 1). The exposure of $30 \mathrm{~min}$ of ischemia and $120 \mathrm{~min}$ of reperfusion to isolated rat hearts produced significant myocardial injury as assessed by increase in the release of CK-MB, $p<0.001$ (Fig. 2) and CTnT, $p<0.001$ (Fig. 3) in the coronary effluent. Moreover, there was also a significant decline in the functional parameters of heart assessed in terms of LVDP and there was a decrease in the value of LVDP during the reperfusion phase in comparison to pre-ischemic state (before ischemia), $p<0.001$ (Table 1). In diabetic rats, there was a significant increase in heart injury in response to $30 \mathrm{~min}$ of ischemia and $120 \mathrm{~min}$ of reperfusion in comparison to normal, nondiabetic rats. In diabetic rats, there was higher release of CK-MB, $p<0.01$ (Fig. 2), and cTnT, $p<0.01$ (Fig. 3), in coronary effluent along with more depressed LVDP value, $p<0.01$ (Table 1 ), in comparison to nondiabetic rats. It suggests that there was more significant myocardial injury in diabetic rats in comparison to nondiabetic rats.

Blood Glucose Levels

Values are mean $\pm \mathrm{SD}_{*}^{*}=\mathrm{p}<0.05$ vs. nondiabetic control; $\wedge=\mathrm{p}<0.05$ vs. RIP in diabetic. RIP: remote preconditioning.

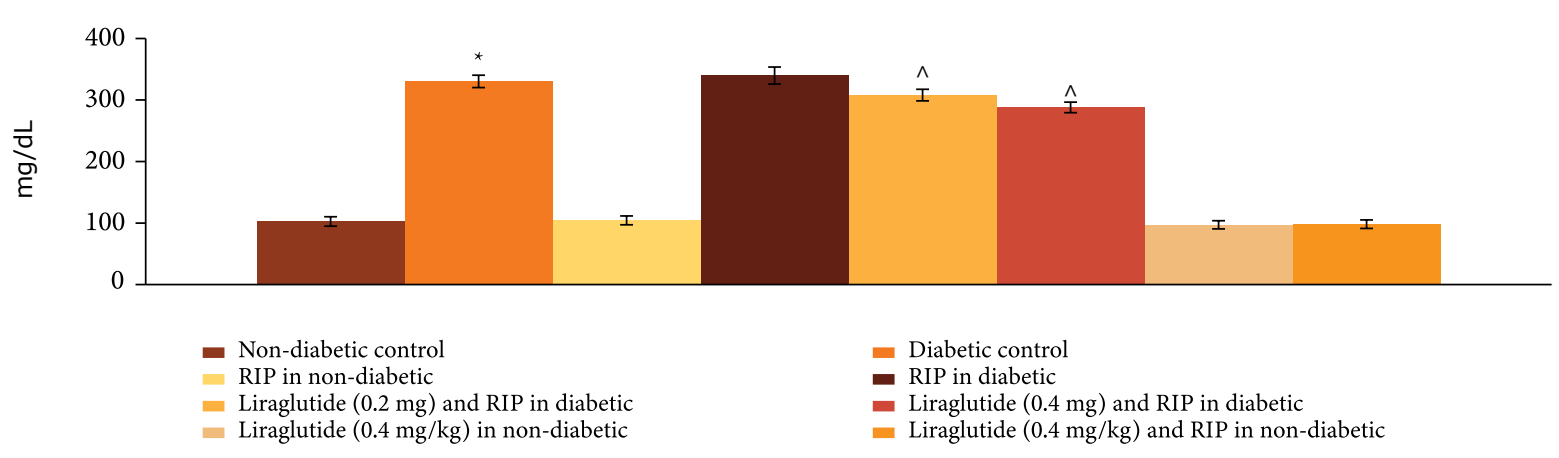

Figure 1 - Effect of different interventions on blood glucose levels, assessed at the end of the 8th week. 


\section{CK-MB}

Values are mean $\pm \mathrm{SD}^{*}=\mathrm{p}<0.05$ vs. nondiabetic during before ischemia; $@=\mathrm{p}<0.05$ vs. nondiabetic control during reperfusion; $\wedge=p<0.05$ vs. RIP in diabetic. RIP: remote preconditioning

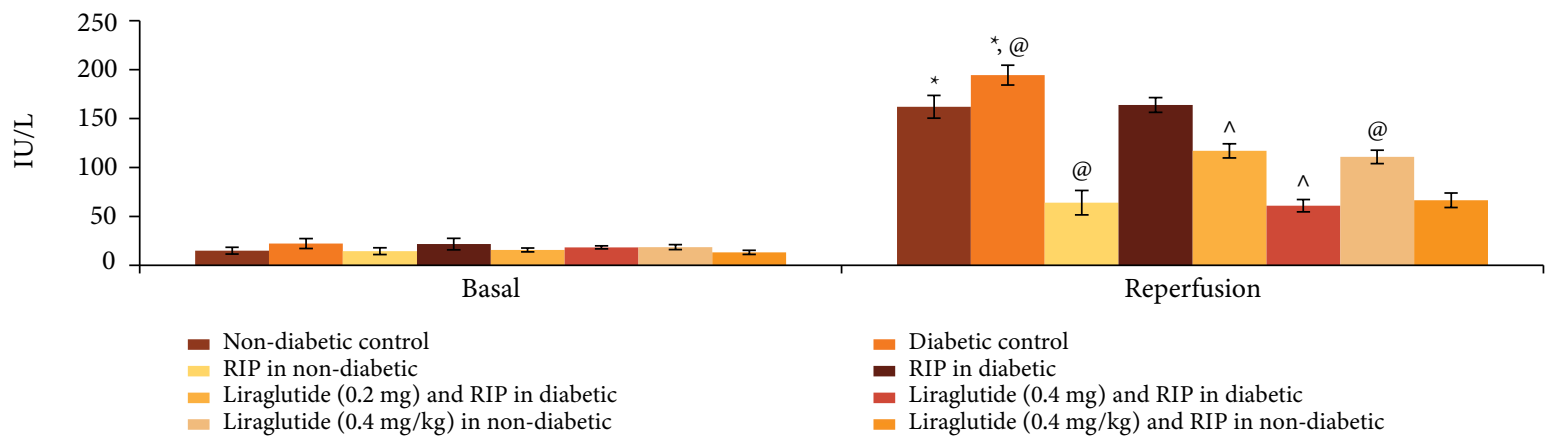

Figure 2-Effect of different interventions on the CK-MB levels, assessed in the coronary effluent before ischemia and during reperfusion.

\section{cTnT}

Values are mean $\pm \mathrm{SD} .{ }^{*}=\mathrm{p}<0.05$ vs. nondiabetic during before ischemia; $@=\mathrm{p}<0.05$ vs. nondiabetic control during reperfusion; $\wedge=\mathrm{p}<0.05$ vs. RIP in diabetic. RIP: remotepreconditioning.

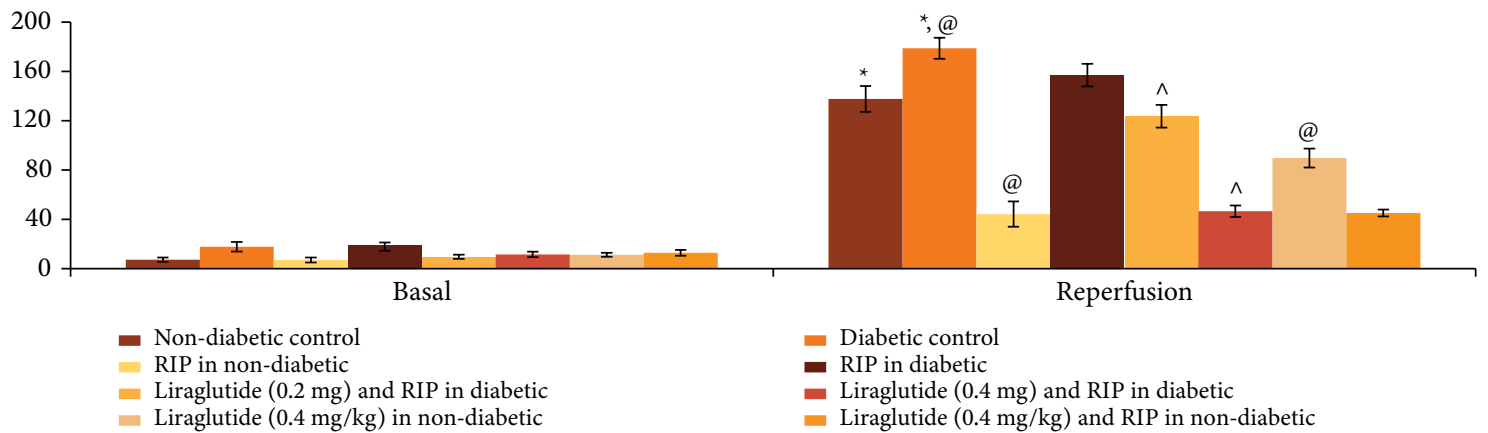

Figure 3-Effect of different interventions on the cTnT levels, assessed in the coronary effluent before ischemia and during reperfusion.

Table 1 - Effect of different interventions on the LVDP values, assessed before ischemia and during reperfusion.

\begin{tabular}{cccc} 
S. No & Experimental & Before ischemia & During reperfusion \\
\hline 1. & Nondiabetic control & $76.50 \pm 3.54$ & $33.50 \pm 3.25^{*}$ \\
2. & Diabetic control & $64.10 \pm 2.41$ & $23.00 \pm 1.77^{@}$ \\
3. & RIP in nondiabetic & $76.37 \pm 2.38$ & $55.75 \pm 2.60^{@}$ \\
4. & RIP in diabetic & $63.75 \pm 2.25$ & $31.30 \pm 2.19$ \\
5. & Liraglutide $(0.2 \mathrm{mg})$ and RIP in diabetic & $72.25 \pm 2.31$ & $45.15 \pm 3.18^{\wedge}$ \\
6. & Liraglutide $(0.4 \mathrm{mg})$ and RIP in diabetic & $70.87 \pm 2.29$ & $58.00 \pm 3.25^{\wedge}$ \\
7. & Liraglutide $(0.4 \mathrm{mg} / \mathrm{kg})$ in nondiabetic & $69.75 \pm 2.37$ & $39.80 \pm 1.45^{@}$ \\
8. & Liraglutide $(0.4 \mathrm{mg} / \mathrm{kg})$ and RIP in nondiabetic & $70.50 \pm 2.56$ & $56.15 \pm 3.44$ \\
\hline
\end{tabular}

Values are mean $\pm \mathrm{SD} .{ }^{*}=p<0.05$ vs. nondiabetic during before ischemia; $@=p<0.05$ vs. nondiabetic control during reperfusion $\wedge=p<0.05$ vs. RIP in diabetic. RIP: remote preconditioning; LVDP: left ventricular developed pressure.

\section{Effect of remote preconditioning on} ischemia-reperfusion induced injury in nondiabetic rats

Remote preconditioning stimulus produced significant delayed cardioprotection (assessed after $24 \mathrm{~h}$ of stimulus) in ischemia-reperfusion subjected nondiabetic rats. There was significant decline in $\mathrm{CK}-\mathrm{MB}, \mathrm{p}<0.001$ (Fig. 2), and cTnT, $p<0.001$ (Fig. 3), levels along with improvement in LVDP values, $p<0.001$ (Table 1), in remote preconditioningsubjected rats. However, the cardioprotective effects 
of remote preconditioning were not observed in streptozotocin-injected diabetic rats and there was no significant decrease in heart biomarkers or increase in heart contractility.

\section{Effects of liraglutide on remote} preconditioning-mediated actions in diabetic rats

Administration of liraglutide $(0.2$ and $0.4 \mathrm{mg} / \mathrm{kg}$ ) in rats restored the cardioprotective effects of remote preconditioning as there was significant decline in heart injury biomarkers, $p<0.01$ (Figs.2 and 3), and improvement in heart contractility (Table 1 ) in a dosedependent manner, $p<0.01$. However, administration of liraglutide $(0.4 \mathrm{mg} / \mathrm{kg})$ in nondiabetic rats did not enhance the cardioprotection offered by remote preconditioning $p>0.05$.

\section{Influence of different interventions on the biochemical parameters in ischemia-reperfusion subjected rats}

In ischemia-reperfusion subjected rats, there was significant decrease in Nrf2 ratio, $p<0.01$ (Fig.4), H2S, $p<0.01$ (Fig.5), and HIF-1 $\alpha$ levels, $p<0.01$ (Fig.6), in the heart homogenates. The decrease in these biochemical parameters was more prominent in diabetic rats. Remote preconditioning restored the Nrf2 ratio, H2Sand HIF-1 $\alpha$ levels selectively in nondiabetic rats $(p<0.01)$, without any significant effect in diabetic rats $p>0.05$. Administration of liraglutide $(0.2$ and $0.4 \mathrm{mg} / \mathrm{kg}$ ) restored the effects of remote preconditioning and there was a significant increase in Nrf2 ratio, H2Sand HIF- $1 \alpha$ levels, $p<0.01$. Liraglutide did not enhance the effects of remote preconditioning on biochemical parameters, $p>0.05$.

\section{Nrf2 Ratio}

Values are mean $\pm \mathrm{SD}^{*}=$ vs. nondiabetic control; $\wedge=\mathrm{p}<0.05$ vs. RIP in diabetic. RIP: remote preconditioning.

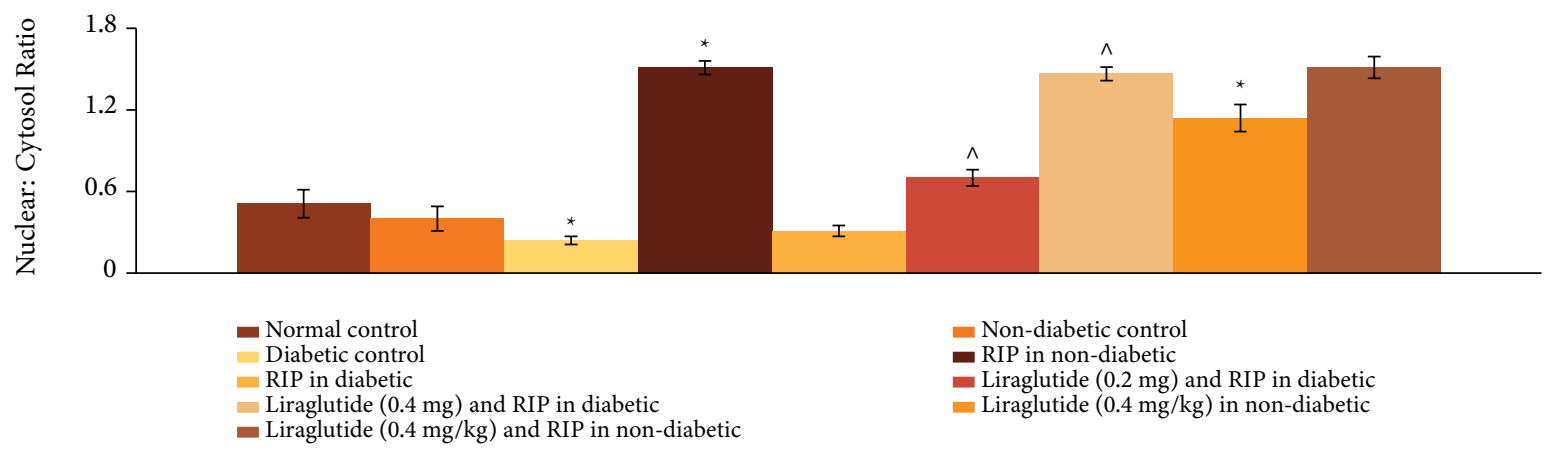

Figure 4-Effect of different interventions on the nuclear cytoplasmic Nrf2 ratio in the heart following ischemia-reperfusion injury.

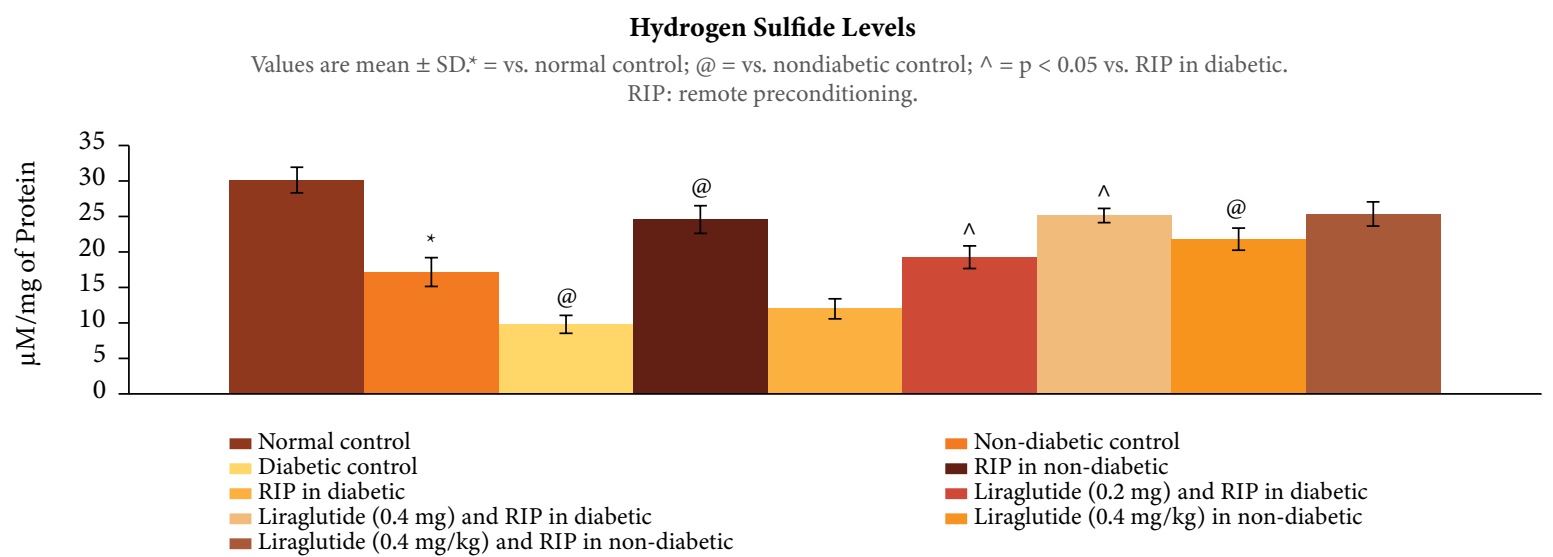

Figure 5 - Effect of different interventions on the H2S levels in the heart following ischemia-reperfusion injury. 


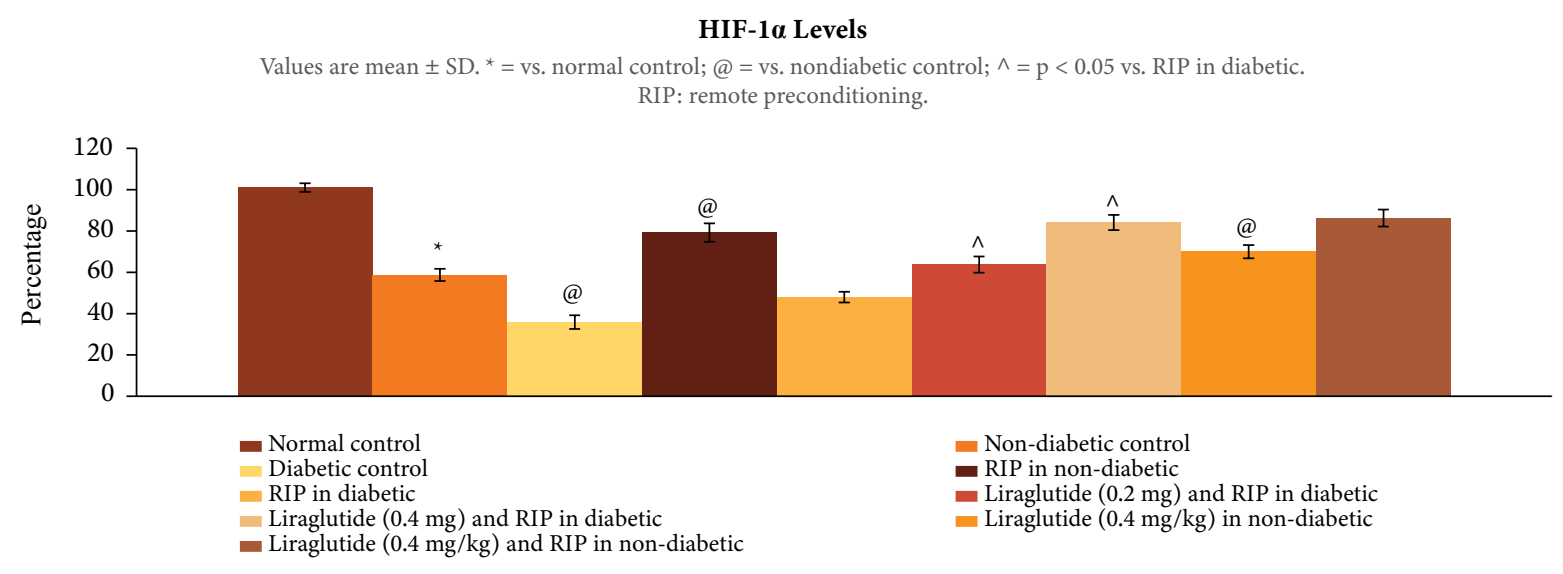

Figure 6 - Effect of different interventions on the HIF-1 $\alpha$ levels in the heart following ischemia-reperfusion injury.

\section{Discussion}

In the present investigation, ischemia-reperfusion produced a significant injury as assessed by an increase in CK-MB and CTnT release along with a decrease in LVDP. The extent of myocardial injury was much higher in diabetic rats in comparison to nondiabetic rats. The present study results showing an increase in myocardial injury in diabetic rats in response to ischemia-reperfusion injury is in consonance with the previous studies ${ }^{23,24}$. In the present study, remote preconditioning attenuated ischemia-reperfusion injury myocardial injury, which was assessed after $24 \mathrm{~h}$ of remote preconditioning stimulus, suggesting that remote preconditioning produced delayed cardioprotective effects in nondiabetic rats. However, the cardioprotective effects of remote preconditioning were not observed in nondiabetic rats. In other words, remote preconditioning failed to attenuate ischemiareperfusion induced myocardial injury in diabetic rats. The present study results showing the attenuated protective effects of remote preconditioning in diabetic rats are in consonance with previously published studies ${ }^{6,25}$. It has been suggested that long standing diabetes mellitus interferes with the endogenous protective mechanism and loss of protective mechanism may contribute to an increase in ischemia-reperfusion injury.

In this study, administration of liraglutide $(0.2 \mathrm{mg}$ and $0.4 \mathrm{mg} / \mathrm{kg}$ ) led to restoration of cardioprotective effects of remote preconditioning and in liraglutide-treated rats, remote preconditioning attenuated ischemiareperfusion injury in a significant manner in diabetic rats. Liraglutide is a glucagon-like peptide 1 agonist and is used in the management of diabetes mellitus ${ }^{8,26}$. Apart from its antidiabetic action, it has been shown to produce beneficial effect on heart, brain and other organs ${ }^{9,27,28,29}$. It is reported to repair the infarcted heart ${ }^{30}$, produce beneficial effects on heart failure ${ }^{31}$. Nevertheless, it is the first study describing the usefulness of liraglutide in restoring the lost late cardioprotective effects of remote preconditioning in diabetic rats.

In the present study, there were significant biochemical alterations in the heart of ischemia-reperfusion subjected rats. There was a significant decrease in the nuclear cytosolic ratio of Nrf2 along with a decrease in the levels of $\mathrm{H}_{2} \mathrm{~S}$ and HIF- $1 \alpha$ in the hearts of ischemia-reperfusion subjected rats. These biochemical alterations were significantly more pronounced in diabetic rats, suggesting that long-term standing hyperglycemia may have adversely affected these biochemical parameters, which may be responsible for increase in myocardial injury in diabetic rats. Interestingly, remote preconditioninginduced cardioprotection was associated with the increase in the levels of $\mathrm{Nrf2}, \mathrm{H}_{2} \mathrm{~S}$ and HIF-1 $\alpha$ in the hearts of ischemia-reperfusion subjected rats. There have been studies showing the key role of $\mathrm{Nrf2}^{14}$, $\mathrm{H}_{2} \mathrm{~S}^{17}$ and HIF-1 $\alpha^{32}$ in remote preconditioning-induced cardioprotection in ischemia-reperfusion subjected rats. However, remote preconditioning failed to increase the levels of these biochemical parameters in diabetic rats, suggesting that failure to increase the levels of $\mathrm{Nrf2}, \mathrm{H}_{2} \mathrm{Sand} \mathrm{HIF}-1 \alpha$ in diabetic rats may be a possible mechanism contributing in attenuating the beneficial effects of remote preconditioning.

In the present study, liraglutide-mediated restoration of cardioprotective effects of remote preconditioning in diabetic rats was associated with a significant increase in the levels of $\mathrm{Nrf2}, \mathrm{H}_{2} \mathrm{~S}$ and HIF-1 $\alpha$ in the heart homogenates. Hypoxia inducible factor is a hypoxia-inducible transcriptional factor, 
which is involved in producing beneficial effects on the heart by virtue of multiple mechanisms, including increase in angiogenesis ${ }^{33}$. There has also been a study showing that liraglutide promotes angiogenesis by increasing the levels of HIF- $1 \alpha^{18}$. Moreover, it is also shown that liraglutide increases the Nrf2 ratio to exert antioxidant effects ${ }^{34}$. However, it is the first study showing the increase in the $\mathrm{H}_{2} \mathrm{~S}$ levels following liraglutide treatment in diabetic rats. Based on the results of the present study, it may be proposed that liraglutide may restore the cardioprotective effects of remote preconditioning in diabetic rats by increasing the expression of $\mathrm{Nrf} 2, \mathrm{H}_{2} \mathrm{~S}$ and HIF- $1 \alpha$.

\section{Conclusion}

Liraglutide has the potential to restore the lost cardioprotective effects of remote preconditioning in diabetic rats by increasing the expression of $\mathrm{Nrf}_{2}, \mathrm{H}_{2} \mathrm{~S}$ and HIF- $1 \alpha$.

\section{Authors' contribution}

Design the study: Wei W; Critical Revision: Wang $L$; Acquisition and analysis of data: Tang $Y$; Technical procedures: Wang L; Manuscript writing: $\mathrm{He} \mathrm{H}$ and Wei W; Final Approval: Wei W

\section{Data availability statement}

All dataset were generated or analyzed in the current study.

\section{Funding}

Not applicable.

\section{Acknowledgments}

The authors are thankful to their institutes for the support and technical services for doing research.

\section{References}

1. Chatham JC, Young ME, Zhang J. Role of O-linked $\mathrm{N}$-acetylglucosamine (O-GlcNAc) modification of proteins in diabetic cardiovascular complications. Curr Opin Pharmacol. 2020;57:1-12. https://doi.org/10.1016/j.coph.2020.08.005

2. Napoli R, Formoso G, Piro S, Targher G, Consoli A, Purrello F. Management of type 2 diabetes for prevention of cardiovascular disease. An expertopinion of the Italian Diabetes Society. Nutr Metab Cardiovasc Dis. 2020;30(11):1926-36. https://doi.org/10.1016/j.numecd.2020.07.012

3. Singh $H$, Kumar $M$, Singh $N$, Jaggi AS. Late Phases of Cardioprotection During Remote Ischemic Preconditioning and Adenosine Preconditioning Involve Activation of Neurogenic Pathway. J Cardiovasc Pharmacol. 2019;73(2):639. https://doi.org/10.1097/FJC.0000000000000634

4. Kosiuk J, Langenhan K, Hindricks G, Bollmann A, Dagres N. Remote ischemic preconditioning in a setting of electrical cardioversion of early onset persistent atrial fibrillation (RIP CAF trial): Rationale and study design. J Cardiol. 2021;77(1):7982. https://doi.org/10.1016/j.jjcc.2020.07.024

5. Sawashita Y, Hirata N, Yoshikawa Y, Terada H, Tokinaga $Y$, Yamakage M. Remote ischemic preconditioning reduces myocardial ischemia-reperfusion injury through unacylated ghrelin-induced activation of the JAK/STAT pathway. Basic Res Cardiol. 2020;115(4):50. https://doi.org/10.1007/s00395020-0809-z

6. Tyagi S, Singh N, Virdi JK, Jaggi AS. Diabetes abolish cardioprotective effects of remote ischemic conditioning: evidences and possible mechanisms. J Physiol Biochem. 2019;75(1):19-28. https://doi.org/10.1007/s13105-01900664-w

7. Rodrigues T, Borges $P$, Mar L, Marques D, Albano M, Eickhoff H, Carrêlo C, Almeida B, Pires S, Abrantes M, Martins B, Uriarte C, Botelho F, Gomes P, Silva S, Seiça R, Matafome P. GLP-1 improves adipose tissue glyoxalase activity and capillarization improving insulin sensitivity in type 2 diabetes. Pharmacol Res. 2020;161:105198. https://doi.org/10.1016/j. phrs.2020.105198

8. Mirabelli M, Chiefari E, Caroleo P, Arcidiacono B, Corigliano DM, Giuliano S, Brunetti FS, Tanyolaç S, Foti DP, Puccio L, Brunetti A. Long-Term Effectiveness of Liraglutide for Weight Management and Glycemic Control in Type 2 Diabetes. Int J Environ Res Public Health. 2019;17(1):207. https://doi. org/10.3390/ijerph17010207

9. Yan W, Pang M, Yu Y, Gou X, Si P, Zhawatibai A, Zhang Y, Zhang $M$, Guo T, Yi X, Chen L. The neuroprotection of liraglutide on diabetic cognitive deficits is associated with improved hippocampal synapses and inhibited neuronal apoptosis. Life Sci. 2019;231:116566. https://doi.org/10.1016/j. Ifs.2019.116566

10. Ougaard ME, Sembach FE, Jensen HE, Pyke C, Knudsen LB, Kvist PH. Liraglutide improves the kidney function in a murine model of chronic kidney disease. Nephron. 2020;144(11):595606. https://doi.org/10.1159/000509418

11. Sassoon DJ, Tune JD, Mather KJ, Noblet JN, Eagleson MA, Conteh AM, Sturek JT, Goodwill AG. Glucagon-Like Peptide 1 Receptor Activation Augments Cardiac Output and Improves Cardiac Efficiency in Obese Swine After Myocardial Infarction. Diabetes. 2017;66(8):2230-40. https://doi.org/10.2337/ db16-1206

12. Zheng R-H, Bai X-J, Zhang W-W, Wang J, Bai F, Yan CP, James EA, Bose HS, Wang N-P, Zhao Z-Q. Liraglutide attenuates cardiac remodeling and improves heart function after abdominal aortic constriction through blocking angiotensin II type 1 receptor in rats. Drug Des Dev Ther. 2019;13:2745-57. https:// doi.org/10.2147/DDDT.S213910 
13. Herajärvi J, Anttila T, Dimova EY, Laukka T, Myllymäki $M$, Haapanen $\mathrm{H}$, Olenchock BA, Tuominen $\mathrm{H}$, Puistola U, Karihtala P, Kiviluoma K, Koivunen P, Anttila V, Juvonen T. Exploring effects of remote ischemic preconditioning in a pig model of hypothermic circulatory arrest. Scand Cardiovasc J. 2017;51(4):233-41. https://doi.org/10.1080/14017431.2017.1319574

14. Zhou C, Li H, Yao Y, Li L. Delayed Remote Ischemic Preconditioning Produces an Additive Cardioprotection to Sevoflurane Postconditioning Through an Enhanced Heme Oxygenase 1 Level Partly Via Nuclear Factor Erythroid 2-Related Factor 2 Nuclear Translocation. J Cardiovasc Pharmacol Ther. 2014;19(6):558-66. https://doi. org/10.1177/1074248414524479

15. Heyman SN, Leibowitz D, Levi IM-Y, Liberman A, Eisenkraft A, Alcalai R, Khamaisi M, Rosenberger C. Adaptive response to hypoxia and remote ischaemia pre-conditioning: a new hypoxia-inducible factors era in clinical medicine. Acta Physiol (Oxf). 2016;216(4):395-406. https://doi.org/10.1111/ apha.12613

16. Kalakech $\mathrm{H}$, Tamareille $\mathrm{S}$, Pons $\mathrm{S}$, Godin-Ribuot $\mathrm{D}$, Carmeliet P, Furber A, Martin V, Berdeaux A, Ghaleh B, Prunier F. Role of hypoxia inducible factor- $1 \alpha$ in remote limb ischemic preconditioning. J Mol Cell Cardiol. 2013;65:98-104. https:// doi.org/10.1016/j.yjmcc.2013.10.001

17. Andreadou I, lliodromitis EK, Rassaf $T$, Schulz $R$, Papapetropoulos A, Ferdinandy P. The role of gasotransmitters $\mathrm{NO}, \mathrm{H} 2 \mathrm{~S}$ and $\mathrm{CO}$ in myocardial ischaemia/reperfusion injury and cardioprotection by preconditioning, postconditioning and remote conditioning. Br J Pharmacol. 2015;172(6):1587606. https://doi.org/10.1111/bph.12811

18. Langlois A, Mura C, Bietiger W, Seyfritz E, Dollinger C, Peronet C, Maillard E, Pinget M, Jeandidier N, Sigrist S. In Vitro and In Vivo Investigation of the Angiogenic Effects of Liraglutide during Islet Transplantation. PLoS One. 2016;11(3):e0147068. https://doi.org/10.1371/journal.pone.0147068

19. Zhu C-G, Luo Y, Wang H, Li J-Y, Yang J, Liu Y-X, Qu H-Q, Wang B-L, Zhu M. Liraglutide Ameliorates Lipotoxicity-Induced Oxidative Stress by Activating the NRF2 Pathway in HepG2 Cells. Horm Metab Res. 2020;52(7):532-9. https://doi. org/10.1055/a-1157-0166

20. Han X, Ding C, Zhang G, Pan R, Liu Y, Huang N, Hou N, Han F, Xu $W$, Sun X. Liraglutide ameliorates obesity-related nonalcoholic fatty liver disease by regulating Sestrin2-mediated Nrf2/HO-1 pathway. Biochem Biophys Res Commun. 2020;525(4):895901. https://doi.org/10.1016/j.bbrc.2020.03.032

21. Adams DM, Yakubu MT. Aqueous extract of Digitaria exilis grains ameliorate diabetes in streptozotocin-induced diabetic male Wistar rats. J Ethnopharmacol. 2020;249:112383. https://doi.org/10.1016/j.jep.2019.112383

22. Watanabe M, Okada T. Langendorff Perfusion Method as an Ex Vivo Model to Evaluate Heart Function in Rats. Methods Mol Biol. 2018;1816:107-16. https://doi.org/10.1007/978-14939-8597-5_8

23. Zhao D, Yang J, Yang L. Insights for Oxidative Stress and mTOR Signaling in Myocardial Ischemia/Reperfusion Injury under
Diabetes. Oxid Med Cell Longev. 2017;2017:6437467. https:// doi.org/10.1155/2017/6437467

24. Xu G, Zhao X, Fu J, Wang X. Resveratrol increase myocardial Nrf2 expression in type 2 diabetic rats and alleviate myocardial ischemia/reperfusion injury (MIRI). Ann Palliat Med. 2019;8(5):565-75. https://doi.org/10.21037/apm.2019.11.25

25. Wider J, Undyala VVR, Whittaker P, Woods J, Chen X, Przyklenk $\mathrm{K}$. Remote ischemic preconditioning fails to reduce infarct size in the Zucker fatty rat model of type-2 diabetes: role of defective humoral communication. Basic Res Cardiol. 2018;113(3):16. https://doi.org/10.1007/s00395-018-0674-1

26. le Roux CW, Astrup A, Fujioka K, Greenway F, Lau DCW, Van Gaal L, Ortiz RV, Wilding JPH, Skjøth TV, Manning LS, Pi-Sunyer $X .3$ years of liraglutide versus placebo for type 2 diabetes risk reduction and weight management in individuals with prediabetes: a randomised, double-blind trial. Lancet. 2017;389(10077):1399-409. https://doi.org/10.1016/S01406736(17)30069-7

27. . Li Y, Bader M, Tamargo I, Rubovitch V, Tweedie D, Pick CG, Greig NH. Liraglutide is neurotrophic and neuroprotective in neuronal cultures and mitigates mild traumatic brain injury in mice. J Neurochem. 2015;135(6):1203-17. https://doi. org/10.1111/jnc.13169

28. Li Y-K, Ma D-X, Wang Z-M, Hu X-F, Li S-L, Tian H-Z, Wang M-J, Shu Y-W, Yang J. The glucagon-like peptide-1 (GLP-1) analog liraglutide attenuates renal fibrosis. Pharmacol Res. 2018;131:102-11. https://doi.org/10.1016/j.phrs.2018.03.004

29. 29. Ekström $K$, Dalsgaard $M$, Iversen $K$, Pedersen-Bjergaard $U$, Vejlstrup N, Diemar SS, Idorn M, Thorsteinsson B, Engstrøm T. Effects of liraglutide and ischemic postconditioning on myocardial salvage after I/R injury in pigs*. Scand Cardiovasc J. 2017;51(1):8-14. https://doi.org/10.1080/14017431.2016. 1197417

30. Qiao H, Ren H, Du H, Zhang M, Xiong X, Lv R. Liraglutide repairs the infarcted heart: The role of the SIRT1/Parkin/mitophagy pathway. Mol Med Rep. 2018;17(3):3722-34. https://doi. org/10.3892/mmr.2018.8371

31. Zhang $Y$, Chen $Q$, Huang $G$, Wang $L$. The influence of liraglutide for heart failure: a meta-analysis of randomized controlled trials. Heart Surg Forum. 2019;22(6):E438-44. https://doi. org/10.1532/hsf.2513

32. Cai Z, Luo W, Zhan H, Semenza GL. Hypoxia-inducible factor 1 is required for remote ischemic preconditioning of the heart. Proc Natl Acad Sci USA. 2013;110(43):17462-7. https://doi. org/10.1073/pnas.1317158110

33. Semenza GL. Hypoxia-Inducible Factor 1 and Cardiovascular Disease. Annu Rev Physiol. 2014;76:39-56. https://doi. org/10.1146/annurev-physiol-021113-170322

34. Deng C, Cao J, Han J, Li J, Li Z, Shi N, He J. Liraglutide Activates the Nrf2/HO-1 Antioxidant Pathway and Protects Brain Nerve Cells against Cerebral Ischemia in Diabetic Rats. Comput Intel INeurosci. 2018;2018:3094504. https://doi. org/10.1155/2018/3094504 